\title{
Development and Validation of a Project Package for Junior Secondary School Basic Science
}

\author{
Nsikak-Abasi Udofia \\ Department of Educational Foundations, Guidance and Counseling, University of Uyo, P.M.B. 1017, Akwa Ibom State, Nigeria \\ *Corresponding Author: nsisong99@yahoo.com
}

Copyright $@ 2014$ Horizon Research Publishing All rights reserved.

\begin{abstract}
This was a Research and Developmental study designed to develop and validate projects for Junior Secondary School Basic Science instruction and evaluation. The projects were developed using the project blueprint and sent for validation by experts in science education and measurement and evaluation; using a project validation scale. They were to rate the project task and skills in terms of their appropriateness and suitability. The projects were later administered on 1584 students. The result showed that the project measures of skills and task were significantly related. The project sub-scale of cognitive, affective and psychomotor was also significantly correlated. The inter-rater reliability index varied from 0.75 to 0.92 . Hence, the projects were recommended for instructing and evaluating Junior Secondary School Basic Science.
\end{abstract}

Keywords Basic Science Instruction, Project Method Of Learning, Junior Secondary School

\section{Introduction}

Project method of teaching is a multipurpose teaching method which can be used for several instructional purposes and for achieving the objectives of the curriculum. With the project, learners develop discipline in learning, productive study habit, multiple educational skills, improved involvement in learning, independent thinking, self-confidence, social responsibility, practice social and democratic modes of behaviour. The project involves learners solving practical problem which could be suggested by the teacher but planned and executed by the students individually or in groups.

Literature has it that between 1590 and 1765 project was used in the academics of architecture in Rome and Paris, between 1765 and 1880 the project became a regular teaching method in the schools of engineering in France, Germany, and Switzerland. In 1865, the project was introduced by William B. Rogers at the Massachusetts Institute of Technology into the United State. From 1880 to 1918 Calvin M. Woodward adapted the project into schoolwork while between 1918 and 1965 Kilpatrick synchronized the project as a construct with the Child-centered and progressive Philosophy of education. These approaches have influenced curriculum development and implementation till date. In the 1970 s, project method was rediscovered as a veritable teaching method in a democratic society in the European countries especially as an important supplement to the traditional teacher-oriented, subject-centered curriculum [c.f. 1-4]

A Project-method-classroom (PMC) focuses on collaboration to solve "purposeful" problems [5]. The project has been defined differently by different scholars. Morgan [6] defined project-based learning as "an activity which students develop an understanding of a topic or issue through some kind of involvement on an actual (or simulation) of real life problem or issue and in which they have some degree of responsibility in designing." On the other hand, Harbor-Peters [7] defined the project as "a special form of take home examination which provides for a topic to be studied at a greater depth than would be covered in a classroom lecture". Udofia [8] defined project as "a special instructional and evaluation tool or problem-solving activity built into a lesson for a more independent interaction between the teacher and the learner such that learning is actualized in the three domains by the learner".

Wilber and Pandered [9] remarked that the project enables students to plan work properly and execute plan skillfully. It also assists in problem-solving, facilities discover and helps in developing initiative and independent thinking. Project encourages originality of thought and logical thinking of learners. It encourages a closer human relationship between the learner and the teacher. It provides an opportunity for the teacher to facilitate the class. However project is difficult to carry out it make demand on cost and time hence require experience in project designing [10].

In addition Ndukwe [11] reported that project teaching methods was significantly better in retention than the method and is therefore the best method to teach skills acquisition and behavioural changes. Projects are used to encourage experimental or hands-on learning by so doing learners master not only project skills, but life skills this includes decision making, problem solving, communicating, and 
ethical abilities. It also encourages positive human relationship, and self concept. Project promotes information management, capacity building and researching ability among teachers and students. In the project, the teacher is seen as a facilitator of knowledge and information [12]. The efficacy of projects is demonstrated by Nsa [13], who conducted an experiment on senior secondary school student's acquisition of production skills in vegetable production. The non-randomized protest, posttest design was on a sample size of 60 students and was analyzed using t-test. The result revealed project enhanced student's performances.

Ogomaka [14] developed projects for the teaching of Mathematics to Junior Secondary Schools students. Three projects were developed for both instructional and evaluation processes. The projects were tried on a simple randomly sampled 240 students drawn from four (4) schools. Ten randomly selected teachers were used in validating the project. The projects were found to have effect on the affective domain of the students. There was linear relationship between the three projects. The raters-reliability was (0.56-0.72). It also showed that these projects increased the interest of the students in Mathematics. However, the study was one-sided having only assessed the affective domain. This left the other two domains untested. The purely experimental design used made the work a little far from actual classroom situation.

Harbor-Peters [7] developed a model Mathematics project for classroom instruction. However, this was not empirically validated. The project was to last for six (6) to eight (8) weeks and they were: To investigate the numeration of Igbo, Yoruba and Hausa up to hundred and justify the system in the characteristics and properties of each of them based on standard numeration; To develop a personal number system and used them to build a numeration system, which may be additive and multiplicative which should not be more than seven numerals; and justify the validity of the new system by writing from one (1) to fifty (50). The project had twelve ability levels from where questions were raised. The project model highlighted the steps necessary for project formation. It demonstrated the possibility of integrating project into the school instructional code. The project was therefore arranged to take the standard format for classroom lesson note. This involved the inclusion of Project Topic, the topic of the project, the time limit, the project objectives, the entry behaviour processes involved in the execution of the projects, relevant and evaluation techniques.

Ogomaka [15] developed four (4) objectives and five (5) hypotheses in an instrumentation research using ten (10) evaluation experts and Mathematics educators, twenty (20) experienced secondary school Mathematics teachers and 120 junior secondary school students in Nsukka. The projects involved were: (i) The use of binary numbers; (ii) Constructing a model; and (iii) Collection and simple data from diverse sources.

The instrument was validated and used in teaching the students. Three marking schemes were made for the project and responses scored by the teachers. The suitability of the project were significant with t-test of $10.8,6.83$ and 13.33 and were relevant with t-test of $8.83,6.83$ and 13.33 at $n=26$, 23 and 25. The cognitive and psychomotor outcomes as presented in the marking schemes were equally significant with $\chi^{2}$ of $16.73,8.83$ and 13.33 for cognitive and $8.83,10.08$ and 4.80 for psychomotor with $n=26,23$ and 25. Experts vetted each ratting. The rater's reliability were found significant with 3.91, 4.21 and 4.77 for cognitive, 3.31, 2.93 and 13.02 for psychomotor. The reliability coefficients were $r_{x x}=0.81,0.83$ and 0.86 for cognitive, and $r_{x x}=0.70,0.72$ ad 0.72 for psychomotor. The F-ratio were 50.41, 112.11 and 122.08 for cognitive; $31.00,8.35$ and 80.21 for psychomotor. These were all significant and the projects were well validated though the number of students was few and the project did not assess the affective domain of the students.

Ezeudu [16] also developed projects in geographical. The project was developed on waste disposal. The purpose was to develop the project task and skills on the Solid Waste disposal for use in teaching and evaluating the SS III geography. The result reveals that the expert highly agreed on each of the task in terms of the language expression and the concept involved. They made use of Yes or No answers. Six projects made a score of 25:0 and one project 15:10. A similar result was obtained in terms of the CRAS and PRAS (Cognitive rating scale and psychomotor Rating scale respectively). The inter-rater reliability coefficient for CRAS and PRAS were 0.85 to 0.95 and 0.73 to 0.87 respectively for the whole projects. It was also observed that the raters did not differ significantly on their ratings of the student with an F-ratio of 0.43 and 0.39 for CRAS and PRAS respectively. The student scores were equally high CRAS ( $\bar{x}=62.2$, SD-13.3); PRAS ( $\bar{x}=58.8$; SD $=12.0)$ and PAS $(\bar{x}=67.3$, $\mathrm{SD}=13.4$ ). The inter-correlation ranged from 0.45 to 0.71 for variable of PRAS and CRAS. These relationships were found significant. The projects were acceptable as presented for validated. It however did not emphasize the instructional part of the project, though it would have been very good for set induction. There was no significant different among the four raters with $F_{(0.05 ; 3.37)}=0.70$ and 0.71 for CRAS and PRAS respectively in which case the null hypothesis were not rejected. The skills were inter-correlated with range from 0.57 to 0.79 .

Projects are found here validated for use in Mathematics and Geography. None was found validated for Basic Science. Basic Science is science designed for the child to develop skills to contribute meaningful and productively to the society and at the same time live a more rewarding life in an ever changing world. Basic science is science taught in the junior secondary school [17]. One of recommended methods for instructing the basic science curriculum is the project.

The Basic Science curriculum is designed to enable the learner to develop interest in science and technology, acquire basic knowledge and skills in science and technology, apply their scientific and technological knowledge and skills to meet societal needs; take advantage of the numerous career opportunities offered by science and technology and become 
prepared for further studies in science and technology. The use of guided inquiry method and learning is implied and each topic is ordered to promote learning to expose students to development in science and technology that will enable them face challenges, make informed decisions, develop survival strategies and learn to live effectively within the global community. The curriculum is made up of four themes namely, you and environment, living and non-living things, you and technology and you and energy. In each of the thematic arranged curriculum are activities. The project is among the suggested activities.

However, the junior secondary school result still shows unacceptable performance in the Basic Sciences. It is certain that the teachers do not teach according to the curricula specifications [18]. For instance, if they were to use the project methods the student performance would have improved $[11,13]$. It is also true that projects are difficult to develop. Since this is so, there is need to develop projects to assist the teachers. The curriculum envisaged this and recommended continuous capacity building for teachers. It was on the strength of these that this study was conducted to answer the question can projects be developed in basic science to assist the teachers to teach according to the curricular specification and at the same time improve student's performance in basic science?

\section{Research Questions}

1. What is the range of the index of agreement, amongst the validators of each project task in terms of its suitability

2. What is the range of the index of agreement, amongst the validators of each project skill in terms of its appropriateness?

3. What is the range of the measure of association, within the cognitive affective and psychomotor outcomes of each project?

4. What is the range of the measure of inter-rater association of each project?

\section{Hypotheses}

1. There is no significant agreement, amongst the validators of each project skill in terms of its suitability

2. There is no significant agreement, amongst the validators of each project skill in terms of its appropriateness?

3. There is no significant difference in the range of the measure of association, within the cognitive affective and psychomotor outcomes of each project?

4. There is no significant difference in the mean scores of the users of the projects by gender.

5. There is no significant difference in the mean scores of the users of the projects by School location

\section{Methodology}

The Design: The study was a research and developmental study. The study was conducted in Ikot Ekpene Education Zone. The sample consisted of 1584 students drawn from eight out of twenty six schools selected by stratified proportionate random sampling technique. The major criteria used for the sampling was school location. Gender occurs naturally in the sample as only one sample sex school is found in the area. Data was analyzed using the Coefficient of Concordance, Chi square, Pearson Product Moment Correlation, Multiple Correlation and the Analysis of Variance

Instrumentation: Several instruments were engaged in this study namely: the project blueprint, the project validation scale and the project itself. The project blueprint was designed to ensure the content validity of the project. It was based purely on the coverage of the performance objectives and the content dimension of the Basic Science curriculum. According to Harbor-Peters (1992) the projects were arranged according to these sub-headings: Project Topic, the Theme, the topics, the time limit, the project objectives, the entry behaviour processes involved in the execution of the projects and evaluation techniques. Action words were used to instruct the project task. The project themes were developed from the Basic Science Curriculum. The validation involved the use of experts in Science education and Measurement and Evaluation. The validation was a continuous process of vetting and corrections until an acceptable standard were. In all, 16 projects were developed. The projects were sent for vetting and face validations after which corrections were effected and the inter rater reliability index calculated. Necessary corrections were made until such a time that such project made an inter-rater reliability index of 0.75 or above and the raters where satisfied with the nature of the project. After this session, the projects were given to independent raters, here known as Validators to rate and score. They were not part of the original vetting and face validation. From their input, the best 12 projects were arrived at so as to obtain one project per term and four based on the thematic areas (one project prepared to assist in revision at the final term of the Junior Secondary school).

The validated project was another instrument for the study. The projects skills were scored by point marking as developed by Ogomaka [7]. The latter stage commenced at the same time in the eight schools. The subject teacher instructed using the project. As the students responded, trained research assistants joined the teachers in rating the students.

\section{Results}

Data in Table 1 were the ratings of the validators based on their reaction on the project validation scale. The indices of agreement amongst the validators ranged from 0.60 to 0.92 . The indices were obtained using the coefficient of concordance $(\mathrm{W})$ of the four (4) raters. 
These indices were tested for significance in Table 1. The W. Coefficient for the twelve (12) projects was significant using $\chi^{2}$ to test their significance. Therefore, there was significant agreement amongst the validators of the projects as defined by their rating on the projects validation scale.

Table 1. The coefficients of concordance (w) and their test of significance of the scores on suitability of the project task validation

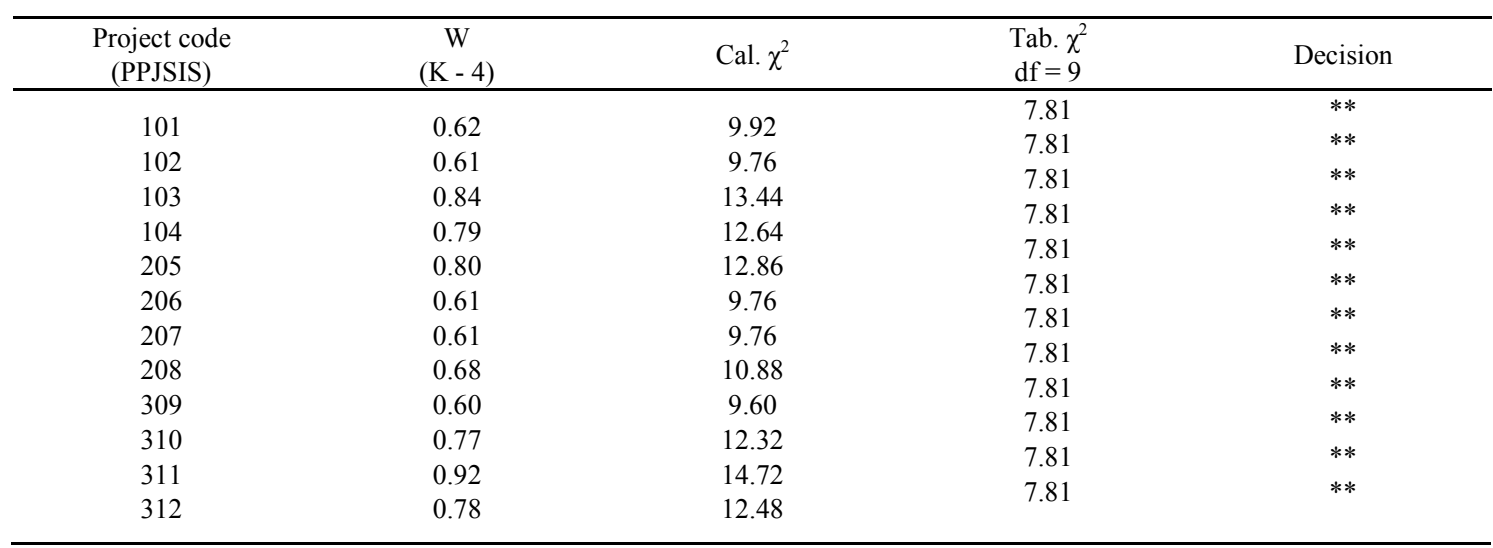

Note $\mathrm{p}^{* *}<.05$ Significant.

Table 2. The coefficients of concordance (W) and their test of significant of the scores appropriateness of the project skill validation

\begin{tabular}{|c|c|c|c|c|}
\hline $\begin{array}{c}\text { Project code } \\
\text { (PPJSIS) }\end{array}$ & $\begin{array}{c}\mathrm{W} \\
(\mathrm{K}-4) \\
\end{array}$ & Cal. $\chi^{2}$ & $\begin{array}{l}\text { Tab. } \chi^{2} \\
\mathrm{df}=27\end{array}$ & Decision \\
\hline & & & 31.41 & $* *$ \\
\hline 101 & 0.88 & 66.88 & 31.41 & $* *$ \\
\hline 102 & 0.98 & 74.48 & 3141 & $* *$ \\
\hline 103 & 0.75 & 57.00 & 31.41 & $* *$ \\
\hline 104 & 0.76 & 57.00 & 31.41 & $* *$ \\
\hline 205 & 0.97 & 73.72 & 31.41 & $* *$ \\
\hline 206 & 0.71 & 53.96 & 31.41 & $* *$ \\
\hline 207 & 0.72 & 54.72 & 31.41 & $* *$ \\
\hline 208 & 0.72 & 54.72 & 31.41 & $* *$ \\
\hline 309 & $\begin{array}{l}0.12 \\
0.74\end{array}$ & $\begin{array}{l}54.12 \\
56.24\end{array}$ & 31.41 & $* *$ \\
\hline .310 & 0.84 & $\begin{array}{l}30.24 \\
63.84\end{array}$ & 31.41 & $* *$ \\
\hline 311 & 0.64 & $\begin{array}{l}05.04 \\
4864\end{array}$ & 31.41 & $* *$ \\
\hline 312 & $\begin{array}{l}0.04 \\
0.65\end{array}$ & $\begin{array}{l}48.04 \\
49.40\end{array}$ & 31.41 & $* *$ \\
\hline
\end{tabular}

Note $\mathrm{p}^{* *}<.05$ Significant.

Data in Table 2 presents the indices of agreement amongst validators, obtained using the project validation scale and computed with the coefficient of concordance. The values ranged from 0.64 to 0.98 .

These indices were tested for significance in table 2. The Coefficient of concordance (W) for the twelve project where tested using $\chi^{2}$ and were found significant. Therefore, there was significant agreement amongst the validators of the project skills as defined by their rating on the project validation scales.

Table 3. Pearson product correlation ( $r$ ) and its test of significance of the cognitive (C), Affective (A) and psychomotor (P) outcomes of each project

\begin{tabular}{|c|c|c|c|c|c|}
\hline $\begin{array}{l}\text { Project code } \\
\text { (PPJSIS) }\end{array}$ & $\mathrm{C} * \mathrm{~A}$ & $\begin{array}{l}\mathrm{r} \text { coefficient. } \\
\mathrm{C} * \mathrm{P} \\
\end{array}$ & $\mathrm{A} * \mathrm{P}$ & $\mathrm{C} * \mathrm{~A} * \mathrm{P}$ & $\begin{array}{c}\text { F. ratio } \\
\mathrm{F}_{(0.05 . \alpha)}=2.00 \\
\end{array}$ \\
\hline 101 & $0.81 * *$ & $0.83 * *$ & $0.76^{* *}$ & 0.87 & $1034.02 * *$ \\
\hline 102 & $0.74 * *$ & $0.94 * *$ & $0.88 * *$ & 0.92 & $1829.66^{* *}$ \\
\hline 103 & $0.83 * *$ & $\begin{array}{l}0.82 * * \\
0.03 * *\end{array}$ & $0.87 * *$ & 0.85 & $864.44 * *$ \\
\hline 104 & $0.76^{* *}$ & $0.93 * *$ & $0.86^{* *}$ & 0.93 & $2126.11 * *$ \\
\hline 205 & $0.81 * *$ & $0.84 * *$ & $0.87 * *$ & 0.85 & $864.44 * *$ \\
\hline 206 & $0.81^{* *}$ & $0.76^{* *}$ & $0.78 * *$ & 0.84 & $795.94 * *$ \\
\hline 207 & $0.93 * *$ & $0.89 * *$ & $0.92 * *$ & 0.93 & $2126.11^{* *}$ \\
\hline 208 & $0.85^{* *}$ & $0.85^{* *}$ & $0.92 * *$ & 0.86 & $943.13 * *$ \\
\hline 309 & $0.80 * *$ & $0.78 * *$ & $0.84 * *$ & 0.82 & $332.00 * *$ \\
\hline 310 & $0.81^{* *}$ & $0.93 * *$ & $0.85 * *$ & 0.93 & $2126.11^{* *}$ \\
\hline 311 & $0.74 * *$ & $0.92 * *$ & $0.86 * *$ & 0.93 & $2126.11 * *$ \\
\hline 312 & $0.72 * *$ & $0.82 * *$ & $0.92 * *$ & 0.83 & $735.30 * *$ \\
\hline
\end{tabular}

Note $\mathrm{p}^{* *}<.05$ Significant.

Data in Table 3 show the correlation between the scores of students on each of the sub - scales. The value of $\mathrm{r}$ ranged thus: 
$\mathrm{C}^{*} \mathrm{P}=0.76-0.94: \mathrm{C}^{*} \mathrm{~A}=0.72-0.93: \mathrm{A} * \mathrm{P}=0.76-0.92$, and $\mathrm{C}^{*} \mathrm{~A} * \mathrm{P}=0.82-.093$ for the twelve projects.

These indices were tested for significance in Table 3 . The $r=$ ratio was tested directly for significance using the $r$ table of significance while the multiple correlations was converted to F ratio and tested for significance accordingly. In all the projects, the correlation's coefficients were significant.

Table 4. The Inter Rater Reliability index of scores from each project using Random model Inter-rater Reliability Index

\begin{tabular}{|c|c|c|c|}
\hline $\begin{array}{l}\text { Project } \\
\text { PPTSIS }\end{array}$ & MSR & MSW & $r_{x x}$ \\
\hline 101 & 74.00 & 7.40 & 0.90 \\
\hline 102 & 85.21 & 10.50 & 0.88 \\
\hline 103 & 79.64 & 14.81 & 0.81 \\
\hline 104 & 79.00 & 14.00 & 0.82 \\
\hline 205 & 65.30 & 2.19 & 0.97 \\
\hline 206 & 102.01 & 26.02 & 0.75 \\
\hline 207 & 86.00 & 9.60 & 0.89 \\
\hline 208 & 110.40 & 7.2 & 0.93 \\
\hline 309 & 109.01 & 9.01 & 0.92 \\
\hline 310 & 109.21 & 15.90 & 0.85 \\
\hline 311 & 100.82 & 4.81 & 0.95 \\
\hline 312 & 82.19 & 12.81 & 0.84 \\
\hline
\end{tabular}

Table 4 presents the inter-raters Reliability indices for all the users of the projects. The indices vary from 0.75 to 0.92 for the twelve (12) projects.

Table 5. The ANOVA table of the scores of male and female users of the project

\begin{tabular}{|c|c|c|c|c|c|c|c|}
\hline Project code (PPJSIS) & $\begin{array}{c}\text { Sources of } \\
\text { Variation }\end{array}$ & $\mathrm{df}$ & SSS & MS & $\mathrm{F}_{\text {(cal) }}$ & Decis & on at $F_{(\mathrm{tab})}=2.000$ \\
\hline \multirow{3}{*}{101} & Between Groups Within & 1 & 234.55 & & \multirow{3}{*}{1.45} & \multirow{3}{*}{\multicolumn{2}{|c|}{$*$}} \\
\hline & Groups & 778 & 125849.28 & $\begin{array}{l}234.55 \\
161.76\end{array}$ & & & \\
\hline & Total & 779 & 126083.83 & 161.76 & & & \\
\hline \multirow{3}{*}{102} & Between Groups Within & 1 & 132.64 & & \multirow{3}{*}{0.82} & \multirow{3}{*}{\multicolumn{2}{|c|}{$*$}} \\
\hline & Groups & 778 & 125849.28 & 132.64 & & & \\
\hline & Total & 779 & 125981.92 & & & & \\
\hline \multirow{4}{*}{103} & Between Groups Within & 1 & 750.57 & & \multirow{3}{*}{4.64} & \multirow{3}{*}{\multicolumn{2}{|c|}{$* *$}} \\
\hline & Groups & 778 & 125849.28 & $\begin{array}{l}750.57 \\
16176\end{array}$ & & & \\
\hline & Total & 779 & 126599.85 & & & & \\
\hline & Between Groups Within & 1 & 245.88 & & & \multirow{3}{*}{\multicolumn{2}{|c|}{$*$}} \\
\hline \multirow{2}{*}{104} & Groups & 778 & 125849.28 & 245.88 & \multirow[t]{2}{*}{1.52} & & \\
\hline & Total & 779 & 126095.16 & & & & \\
\hline \multirow{4}{*}{205} & Between Groups Within & 1 & 282.78 & & \multirow{3}{*}{1.71} & \multirow{3}{*}{\multicolumn{2}{|c|}{$*$}} \\
\hline & Groups & 780 & 128988.86 & 282.78 & & & \\
\hline & Total & 781 & 129271.64 & & & & \\
\hline & Between Groups Within & 1 & 385.31 & & \multirow{3}{*}{2.33} & \multirow{3}{*}{\multicolumn{2}{|c|}{$* *$}} \\
\hline \multirow[b]{2}{*}{206} & Groups & 780 & 128988.86 & 385.31 & & & \\
\hline & Total & 781 & 129374.17 & & & & \\
\hline \multirow{4}{*}{207} & Between Groups Within & 1 & 135.60 & & \multirow{3}{*}{0.82} & \multirow{3}{*}{\multicolumn{2}{|c|}{$*$}} \\
\hline & Groups & 780 & 128988.86 & 135.60 & & & \\
\hline & Total & 781 & 129124.46 & & & & \\
\hline & Between Groups Within & 1 & 289.40 & & \multirow{3}{*}{1.75} & \multirow{3}{*}{\multicolumn{2}{|c|}{$*$}} \\
\hline \multirow[b]{2}{*}{208} & Groups & 780 & 128988.86 & $\begin{array}{l}289.40 \\
165.37\end{array}$ & & & \\
\hline & Total & 781 & 129278.26 & 165.37 & & & \\
\hline \multirow{3}{*}{309} & Between Groups Within & 1 & 320.76 & & & \multirow{3}{*}{1.83} & \multirow{3}{*}{$*$} \\
\hline & Groups & 798 & 139873.44 & 320.76 & & & \\
\hline & Total & 799 & 140194.20 & & & & \\
\hline & Between Groups Within & 1 & 1009.61 & & & & \\
\hline 310 & Groups & 798 & 139873.44 & 1009.61 & 5.76 & & $* *$ \\
\hline & Total & 799 & 140883.05 & 175.28 & & & \\
\hline & Between Groups Within & 1 & 334.78 & 334.78 & & & \\
\hline & Groups & 798 & 139873.44 & 175.28 & 1.91 & & $*$ \\
\hline 311 & Total & 799 & 140208.22 & & & & \\
\hline & Between Groups Within & 1 & 143.73 & & & & \\
\hline & Groups & 798 & 139873.44 & 143.73 & 0.82 & & $*$ \\
\hline 312 & Total & 799 & 140017.17 & 175.28 & & & \\
\hline
\end{tabular}


From Table 5 the calculated $F$ value was greater than the critical $F$ value of 2.00 in three (3) projects: 103 ( $F=4.64), 206$ $(\mathrm{F}=2.33)$ and $310(\mathrm{~F}=5.76)$. There were therefore significant differences in three (3) projects between the scores of the male and female users of the projects. There were no significant differences in projects between the scores of the male and female users in nine projects.

Table 6. The ANOVA table of the Scores of Urban and Rural Users of the Project

\begin{tabular}{|c|c|c|c|c|c|c|}
\hline Project code (PPJSIS) & $\begin{array}{c}\text { Sources of } \\
\text { Variation }\end{array}$ & df & SSS & MS & $\mathrm{F}_{\text {(cal) }}$ & Decision at $\mathrm{F}_{\text {(tab) }}=2.000$ \\
\hline \multirow{3}{*}{101} & Between Groups & 1 & 125.131 & \multirow{3}{*}{$\begin{array}{c}125.125 \\
178.75\end{array}$} & \multirow{3}{*}{0.70} & \multirow{3}{*}{$*$} \\
\hline & Within Groups & 1582 & 232036.14 & & & \\
\hline & Total & 1583 & 232161.27 & & & \\
\hline \multirow{3}{*}{102} & Between Groups Within & 1 & 321.75 & \multirow{3}{*}{$\begin{array}{l}321.75 \\
178.75\end{array}$} & \multirow{3}{*}{1.80} & \multirow{3}{*}{ * } \\
\hline & Groups & 1582 & 231036.14 & & & \\
\hline & Total & 1583 & 232357.89 & & & \\
\hline \multirow{4}{*}{103} & Between Groups Within & 1 & 146.58 & \multirow{3}{*}{$\begin{array}{l}146.58 \\
178.75\end{array}$} & \multirow{3}{*}{0.82} & \multirow{3}{*}{ * } \\
\hline & Groups & 1582 & 232036.14 & & & \\
\hline & Total & 1583 & 232182.72 & & & \\
\hline & Between Groups Within & 1 & 137.64 & \multirow{3}{*}{$\begin{array}{l}137.64 \\
178.75\end{array}$} & \multirow{3}{*}{0.77} & \multirow{3}{*}{$*$} \\
\hline \multirow[b]{2}{*}{104} & Groups & 1582 & 232036.14 & & & \\
\hline & Total & 1583 & 232173.78 & & & \\
\hline \multirow{4}{*}{205} & Between Groups Within & 1 & 400.00 & \multirow{3}{*}{$\begin{array}{l}400.00 \\
187.79\end{array}$} & \multirow{3}{*}{2.13} & \multirow{3}{*}{$* *$} \\
\hline & Groups & 1470 & 276239.09 & & & \\
\hline & Total & 1471 & 276639.09 & & & \\
\hline & Between Groups Within & 1 & 114.55 & \multirow{3}{*}{$\begin{array}{l}114.55 \\
187.79\end{array}$} & \multirow{3}{*}{0.61} & \multirow{3}{*}{ * } \\
\hline \multirow{3}{*}{206} & Groups & 1470 & 276239.09 & & & \\
\hline & Total & 1471 & 276353.64 & & & \\
\hline & Between Groups Within & 1 & 362.43 & \multirow{3}{*}{$\begin{array}{l}362.43 \\
187.79\end{array}$} & \multirow{3}{*}{1.93} & \\
\hline \multirow{2}{*}{207} & Groups & 1470 & 276239.09 & & & * \\
\hline & Total & 1471 & 276601.52 & & & \\
\hline & Between Groups Within & 1 & 420.65 & & & \\
\hline 208 & Groups & 1470 & 276239.09 & $\begin{array}{l}420.65 \\
18779\end{array}$ & 2.24 & $* *$ \\
\hline 208 & Total & 1471 & 276659.74 & & & \\
\hline & Between Groups Within & 1 & 125.89 & & & \\
\hline & Groups & 1310 & 253901.37 & 125.89 & 0.65 & $*$ \\
\hline 309 & Total & 1311 & 254027.26 & 193.67 & & \\
\hline & Between Groups Within & 1 & 143.32 & & & \\
\hline & Groups & 1310 & 253901.37 & 143.32 & 0.74 & $*$ \\
\hline 310 & Total & 1311 & 254170.58 & 193.67 & & \\
\hline & Between Groups Within & 1 & 122.01 & & & \\
\hline & Groups & 1310 & 253901.37 & $\begin{array}{l}122.01 \\
193.67\end{array}$ & 0.63 & $*$ \\
\hline 311 & Total & 1311 & 254023.38 & 193.67 & & \\
\hline & Between Groups Within & 1 & 100.71 & & & \\
\hline 312 & Groups & 1310 & 253901.37 & 100.71 & 0.52 & $*$ \\
\hline & Total & 1311 & 254002.08 & 193.67 & & \\
\hline
\end{tabular}

Note $\mathrm{p}^{* *}<.05$ Significant.

From Table 4 the $\mathrm{F}$ values were greater than the critical $\mathrm{F}$ test value of 2.00 in two (2) projects $205\left(\mathrm{~F}={ }_{(05)}, 2.13\right)$; $208(\mathrm{~F}(.05)=2.24)$. There were therefore significant differences in two (2) of the projects between the scores of the urban and rural users of the project. There were no significant differences in ten (10) projects between the scores of the urban and rural users of the projects.

\section{Discussion}

The (W) ratio indices obtained for the projects task suitability ranged from 0.60 to 0.92 while that of the project skills appropriateness ranged from 0.64 to 0.98 and were found significant meaning that there was significant agreement among the validators. Past studies arrived at similar conclusion but used different methods. In Ezeudu [16] the ratings were tested for significant with the use of the Analysis of Variance. The result revealed that there was no significant differences between the ratings of the validators used at $\mathrm{F}_{(0.05,2.37)}=0.70$ and 0.71 for CRAS and PRAS respectively. Ogomaka [15] used t-test to test for the significant of his project task and skills. The tasks were significant with $\mathrm{t}=8.83,6.83$ and 13.33 . The tasks were tested for significant with $\mathrm{t}=8.83,6.83$ and 13.33 with $\mathrm{n}=26$.

The cognitive, affective and psychomotor behavioral outcomes were inter correlated, in this study to obtain $\mathrm{C}^{*} \mathrm{~A}=$ $0.72-0.93 ; \mathrm{C} * \mathrm{P}=0.76-0.94 ; \mathrm{A}^{*} \mathrm{P}=0.76-0.92 ; \mathrm{C}^{*} \mathrm{~A} * \mathrm{P}=$ $0.82-0.93$ Ezeudu [16] made a range from 0.46 to 0.81 . The criterion related validity index was also obtained using the Pearson Product Moment this falls between 0.42 and 0.56 . The content validity had been determined by using the test blue print to generate skills and a series of face validation.

The significant index of agreement amongst the experts 
indicates that the validators responded in similar manner to the project tasks and skills. To test for significant of the measures of the inter-rater reliability index the grades of the two evaluators, were correlated using the Pearson Product Moment, $r$, which ranged between 0.75 and 0.92 . This range was about the range obtained by Ogomaka [15], 0.56-0.72; Ezeudu [16], 0.85-0.96; 0.85-0.95 Ogomaka [15] 0.70-0.86 and; Ezeudu [16] 0.73 to. 87 in their projects. The indices of inter-rater reliability observed in this work are acceptable for this project especially as they are designed for instructional and evaluation purposes.

They were tested and found significant. It is therefore certain that the making guide could function properly and that the raters and users could interact in the project with limited unsystematic error-error of measurement. In the projects the norm groups were gender (male, female) and school location (Urban, rural). There was no distinctive observation in the performance within each of the norm groups.

Apart from three projects, the differences were not significant. The absence of gender differences in projects were also the observations of Ogomaka [15] and Ezeudu [16]. However Ezeudu observes significant difference in one of the affective scale in favor of the female in generally project seems not to be gender biased. Furthermore, School location was also not affecting the projects, both urban and rural schools achieved similarly in the projects and significant differences were observed only in two. This was one of the properties rated by the validators. The general view was that the projects were useable. Ogomaka [14, 15] and Ezeudu [16] all reported that their project were useable. Harbor-Peters [7] made the same observation. They recommended the need to train teachers on how to use the projects. When the teachers instruct according to the curricula specification using the projects and other recommended methods and strategies there will be improvement in the performance of students in basic Science as observed by Ndukwe [11] , Ozoji \& Dung [18], Harbor-Peters [7] and Nsa [13].

It is observed from the result that the indices obtained have met the psychometrics standard of other validated projects. It was also observed that the projects can be used in different schools location and by the males and females. Since projects method is one of the recommended teaching methods in Basic science and The Basic science is designed to develop scientific and problem -solving skills these projects will be very useful in instructing and evaluating these skills. It is certain that the projects should be recommended as an innovation in Basic science instruction and evaluation; the developed projects will enable teachers instruct the subject and at the same time acquired skills in developing projects. By implication, this project will enhance the implementation of Basic Science curriculum in the junior secondary school. This will in turn bring about improve performance among the junior secondary school students. It is hope that, the teachers who will use this project will additionally developed skill in project development which will result in development of more projects.

\section{Conclusion}

From the study, projects can be developed and validated for use in the Basic Science class. The result revealed that the following psychometrics properties for the projects: the indices of the suitability of the project tasks were from 0.60 to 0.92 and were significant. The indices of the appropriateness of the project skills were from 0.64 to 0.97 and were significant. The range of the measure of association, within the cognitive affective and psychomotor outcomes of each projects were thus: $\mathrm{C} * \mathrm{P}=0.76-0.94$ : $\mathrm{C}^{*} \mathrm{~A}=0.72-0.93$ : $\mathrm{A} * \mathrm{P}=0.76-0.92 ; \mathrm{C}^{*} \mathrm{~A} * \mathrm{P}=0.82-0.93$ for the twelve projects and all were significant. The range of the measure of inter-raters reliability of each project was from 0.75 to 0.92 for the twelve (12) projects. There were no significant differences in the performance of students in the projects between the scores of the male and female users of the projects and the urban and rural users except in three and two projects respectively.

Hence, the psychometrics properties of the projects where of high quality and met the acceptable standards for the projects validation and could be used in Ikot Ekpene and anywhere in Nigeria where the Basic science curriculum is used. The projects can also be used elsewhere where a related curriculum is utilized. The projects generally were found to be suitable, appropriate, and usable for the teaching and evaluating Basic Science for different variety of students as it was in accordance with the international acceptable best practice for project validation. Teachers should use, adopt, adapt or modify the projects to suit their classrooms and environmental demands.

\section{Recommendations}

The following recommendations are made based on the results of the study:-

(1). As these projects have gone through the processes of validation and found to enhance performance, they are therefore recommended to the teachers to adopt and adapt for use in the basic science instructions and evaluation.

(2). As the projects have been found quite innovative for the teaching and evaluation of Basic science, teachers are encouraged to use projects in their teaching and evaluation.

(3). The study has also revealed that the use of these projects enhances students' performance in basic science. Therefore, curriculum planners avail with them for teaching and evaluation.

(4). As the projects have been successfully used here for evaluation processes, examination agencies should introduced projects into the evaluation of integrated science.

(5). Basic science textbook writers and other project developers may use these projects as guides for developing future projects. 


\section{REFERENCES}

[1] Ask a question (2013). Http//www.answers.com/library/Edu cationa+Encyclopedia-acid 13575999.

[2] Helm, H., \& Katz, G. (20010 Young Investigators: The Project Approach in the Early Years New York: Teachers College Press.

[3] Katz, G., and Chard, Sylvia C. (1989) Engineering Children's Minds: The Project Approach Norwood, NJ Ablex Publishing.

[4] Knoll, (1995). "The project Method: Its Origin and International Influence." In Progressive Education across the Continents. A Handbook, ed. Volker Lenhart and Herman Rohrs. New York: Lang.

[5] Knoll (1997). The Project Method: Its Vocational Education Origin and International Development. Journal of Industrial Teacher Education 34, 59-80. Kilpatrick, William Heard (1918). The Project Method. Teachers College Record.

[6] Morgan, A. (1983). Theoretical Aspect of Project Based Learning in Higher Education. British Journal of Educational Technology, 1, $14-26$.

[7] Harbor-Peters, V. F. A. (1992). Model Mathematics Project and its Application in Mathematics. Abacus, 22, $79-80$.

[8] Udofia, N. A. (1999). Development and Validation of Project Package for Junior Secondary School Integrated Science. Unpublished Ph.D. Thesis: University of Nigeria, Nsukka.

[9] Willber, G. O. \& Pandered, N. C. (1973) Industrial Arts in

[10] Bello, J. Y. (1981). Basic Principles of teaching Ibadan. Spectrum books Limited and John Wiley \& Son.

[11] Ndukwe, U. N. (1985). Immediate Achievement and Retention in Expository Versus. Project centered method of instruction in biology. In 26th STAN conference proceeding. Stan place Abuja.

[12] Gutex L. (2009). New Perspective on Philosophy and Education. Pearson Education, Inc. ISBN 0-205-59433-6.

[13] Nsa, E. O. (2002). Effect of demonstration and project method of teaching on senior secondary students skills Acquisition in vegetable production. Journal of Education Innovator (1), 8-95.

[14] Ogomaka, P. M. C. (1989). Projects in Junior Secondary School Mathematics. Implications for Teaching Learning and Continuous Assessment. Unpublished Ph.D. Thesis, Faculty of Education, University of Nigeria, Nsukka.

[15] Ogomaka, P. M. C. (1997). Development of Some Projects for Assessing Junior Secondary School Performance in Mathematics. Abacus, 21, $29-42$.

[16] Ezeudu, S. A. (1998). Development and Validation of a Project on Solid Waste Disposal for Assessing Learning Outcomes in Senior Secondary (SSIII) Geography' Review of Education, XV, $188-127$.

[17] NERDC (2008). National Curriculum for Junior Secondary School Basic Science. Lagos: United Printers Nigeria Ltd.

[18] Ozoji, B. E., \& Dung, M. D. (2013). A study of students Perception and achievement in Basic science: implication for attending the millennium Development Goals. International Journal Research in Science Technology and mathematics Education. 1(2)35- 43 